\title{
Arcabouço Pedagógico combinado com o glossário técnico de computação em LIBRAS: uma experiência com Lego Mindstorms NXT
}

\author{
Rafael Pinto Granada - PPGEC/FURG - rafaelgranada@furg.br \\ Silvia Silva da Costa Botelho - C3/FURG - silviacb@ furg.br \\ Regina Barwaldt -C3/FURG - reginabarwaldt@ furg.br
}

\begin{abstract}
Resumo: A comunidade surda brasileira conquistou direitos na área da educação e, nos últimos anos, com o aumento da matrícula de surdos em instituições de ensino, há necessidade de desenvolver novos sinais em LIBRAS (Língua Brasileira de Sinais) para termos técnicos específicos de cursos em diversas áreas do conhecimento. Este trabalho visa a elaboração de um glossário computacional de sinais em LIBRAS com as principais palavras reservadas do Lego Mindstorms NXT como estímulo ao raciocínio lógico em pessoas surdas. O trabalho realizou-se em uma Escola de Ensino Médio Bilíngue com 4 alunos entre 14 e 15 anos de idade. Atividades de programação voltadas ao movimento veicular e educação no trânsito foram realizadas. Como forma de validação da proposta, utilizou-se categorias de avaliação pedagógica e análise de conteúdo. Este kit de robótica educacional combinado com o glossário demonstrou a capacidade de desenvolver raciocínio lógico que seria dificultado pela barreira linguística. Conclui-se que os sinais desenvolvidos para o glossário permitem que os surdos acessem termos complexos de computação, proporcionando as mesmas possibilidades de desenvolvimento educacional de seus colegas ouvintes.
\end{abstract}

Palavras-chave: glossário, raciocínio lógico, lego mindstorms NXT, surdo, LIBRAS.

\section{Pedagogical framework combined with the LIBRAS technical glossary: an experience with Lego Mindstorms NXT}

Abstract: The Brazilian deaf community has gained rights in the area of education, and in recent years, with the increase of the enrollment of deaf people in educational institutions, there is a need to develop new signs in LIBRAS (Brazilian Sign Language) for specific technical terms of courses in several areas of knowledge. This work aims the elaboration of a computational glossary of signs in LIBRAS with the main reserved words of Lego Mindstorms NXT as a stimulus to the logical reasoning in deaf people. The work was carried out in a Bilingual High School with 4 students between 14 and 15 years old. Activities of programming directed to the vehicular movement and education in the traffic were realized. As a form of validation of the proposal, categories of pedagogical evaluation and content analysis were used. This educational robotics kit combined with the glossary demonstrated the ability to develop logical reasoning that would be hampered by the language barrier. It is concluded that the signs developed for the glossary allow the deaf to access complex terms of computation, providing the same possibilities of educational development as their fellow listeners.

Keywords: glossary, logical reasoning, lego mindstorms NXT, deaf, LIBRAS. 


\section{INTRODUÇÃO}

Os surdos após o reconhecimento da Língua Brasileira de Sinais (LIBRAS) como segunda língua oficial brasileira por meio da Lei $10.436 / 2002^{1}$ asseguram o seu direito de expressão nos diversos espaços da sociedade. Outro direito adquirido foi o sancionamento da Lei 13.409/2016 ${ }^{2}$ que inclui pessoas com deficiência no sistema de cotas adotado pelas universidades e escolas técnicas federais brasileiras. Aos surdos que alcançam os cursos de nível técnico e superior enfrentam o problema das disciplinas que possuem termos complexos, adequados às suas especificidades, sem tradução em língua de sinais, prejudicando seu aprendizado (MARTINS, 2017). A LIBRAS é uma língua em construção e a quantidade de sinais para termos técnicos de algumas profissões é insuficiente (SILVA, 2011) e relacionado à área da computação este cenário não é diferente. Motivados a resolver essa problemática, o trabalho tem como objetivo elaborar sinais técnicos de computação e estimular o raciocínio lógico de alunos surdos.

\section{EMBASAMENTO TEÓRICO}

A teoria da compensação considera o defeito ou a deficiência, ausência ou um limite capaz de ser superado. Vygotsky (2012) leva em conta não só a gravidade da dificuldade, mas também a eficiência da estratégia pedagógica utilizada para ajudar a superar o problema do surdo. Partindo dessa teoria, os glossários de sinais em LIBRAS podem auxiliar no desenvolvimento cognitivo, além de propiciar e facilitar a comunicação entre usuários surdos e ouvintes, uma vez interativos. Vygotsky ainda cita como uma abordagem via mecanismos compensatórios nos seus estudos em defectologia ${ }^{3}$.

\section{METODOLOGIA}

A falta de sinais na área da computação evidenciou a necessidade de elaborar um glossário computacional de termos técnicos em LIBRAS. Sendo assim, para sua construção, fez-se necessária a realização de 4 etapas:

$\left.1^{a}\right)$ Pesquisar um software na literatura, que estimulasse o raciocínio lógico e pudesse ser adequado ao público surdo. Para contribuir no processo de construção do glossário, os autores contaram com a ajuda de duas colaboradoras que atuam como intérpretes de LIBRAS. Foram pesquisados diversos ambientes de programação tais como Alice $^{4}$ e o Scratch ${ }^{5}$, no entanto, optou-se pelo Lego Mindstorms NXT ${ }^{6}$. Pois os indivíduos surdos normalmente apresentam capacidade de abstração reduzida e o ambiente escolhido possibilita projetar de forma concreta os conceitos abstratos da programação, favorecendo a aprendizagem (GRANADA, 2018). O Lego Mindstorms NXT é um kit de equipamentos para robótica direcionado à educação tecnológica que permite a criação de robôs e, por meio de programação, são capazes de reagir a movimentos, obstáculos e cores com um grau de precisão satisfatório.

\footnotetext{
${ }^{1}$ Sobre a Lei 10.436, acesse a URL: http://www.planalto.gov.br/ccivil_03/leis/2002/L10436.htm

${ }^{2}$ Sobre a Lei 13.409, acesse a URL: http://www.planalto.gov.br/ccivil_03/leis/2002/L10436.htm

${ }^{3}$ A defectologia é uma área dedicada a estudar o processo de desenvolvimento qualitativo das pessoas com deficiência, nesse caso, dos surdos.

${ }^{4}$ Para maiores informações sobre o Alice, acessar a URL: https://www.alice.org/

${ }^{5}$ Para maiores informações sobre o Scratch, acessar a URL: https://scratch.mit.edu/

${ }^{6}$ Para mais informações, acessar a URL: https://www.lego.com
} 
$2^{\text {a) }}$ Escolher as palavras reservadas do Lego Mindstorms NXT para incorporar ao glossário. Dentre elas foram escolhidas 32. O critério utilizado na escolha palavras possibilitou a introdução de conceitos sobre programação para iniciantes.

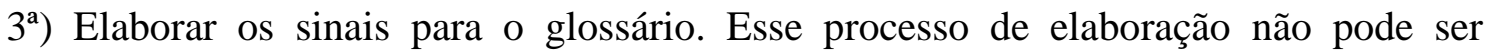
executado arbitrariamente, os sinais possuem uma sequência específica de gestos, visando facilitar e objetivar o entendimento da informação por parte do público surdo (GRANADA, 2018). Para elaborar cada sinal, foi levado em consideração a configuração das mãos, ponto de articulação, movimento, disposição e orientação dos gestos e região de contato (SILVA, 2011).

$4^{a}$ ) Desenvolver a interface do glossário. O glossário foi desenvolvido e pode ser acessado pela comunidade surda ou interessados em geral via $s i t e^{7}$ do grupo InfoEduc ${ }^{8}$. Para a primeira versão desenvolvemos uma interface acessível e intuitiva, adaptada à realidade do surdo, pois nesses indivíduos, a comunicação se estabelece por meio visual ao contrário dos ouvintes que é concebida via oral e auditiva (PEREIRA, 2016). No glossário, cada termo técnico possui dois vídeos, o primeiro deles é o sinal propriamente dito e o segundo é a sua descrição. Esse formato é o mesmo utilizado pelo glossário de LIBRAS da UFSC ${ }^{9}$. A interface do glossário é apresentada na Figura 1.

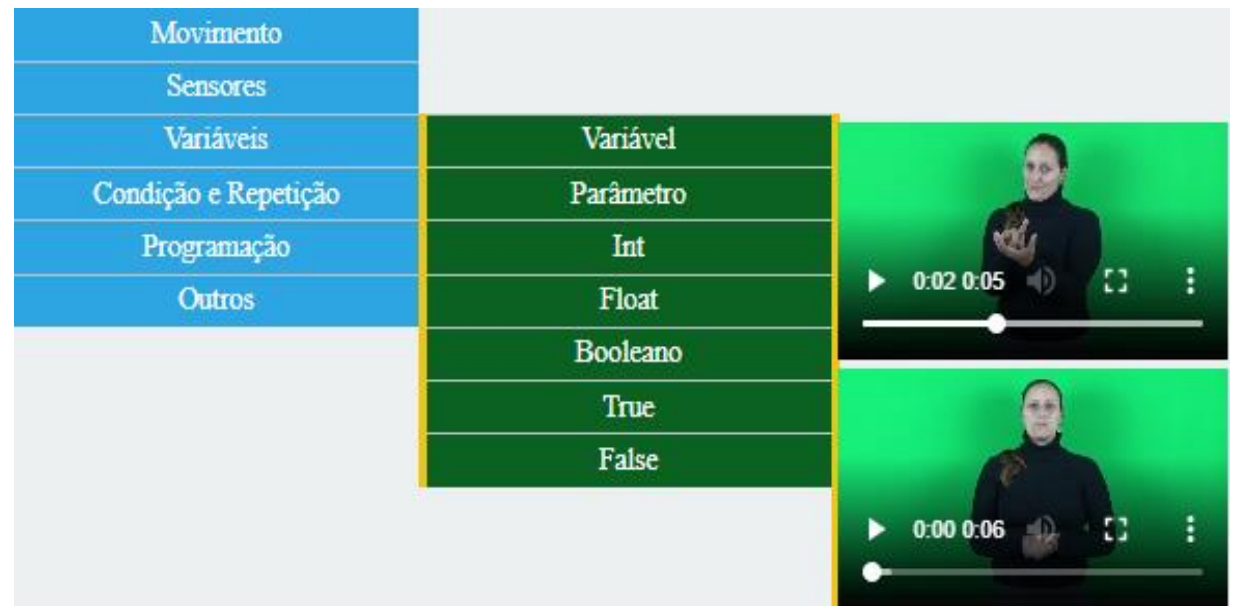

Figura 1 - Glossário com termos do Lego Mindstorms NXT

No entanto, o processo de construção do glossário é apresentado na Figura 2.

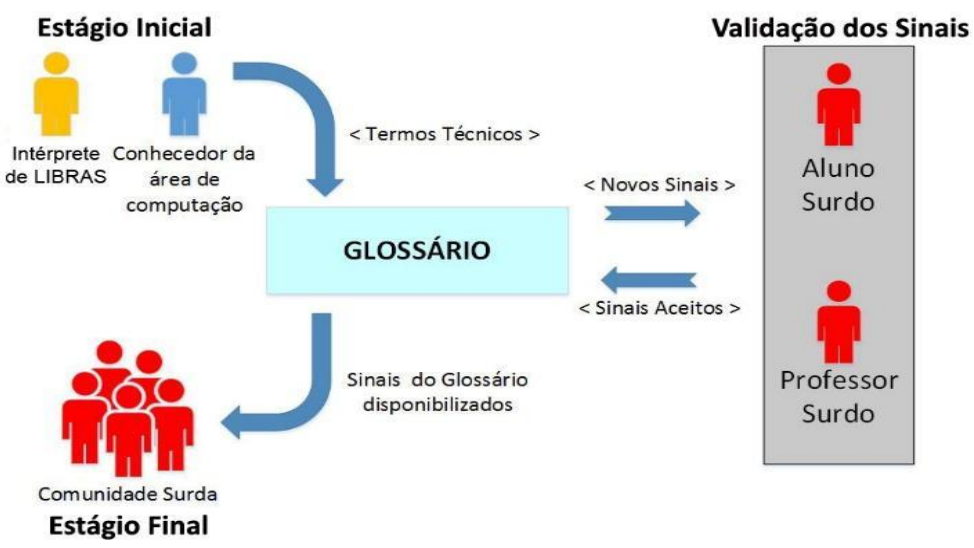

Figura 2 - Processo de construção do glossário

\footnotetext{
${ }^{7} \mathrm{O}$ glossário computacional pode ser acessado em http://200.132.77.56:3380/Glossario/Glossario.html

${ }^{8}$ Grupo de pesquisa de Informática na Educação do C3 da FURG, acessar: http://infoeduc.c3.furg.br

${ }^{9} \mathrm{O}$ glossário da UFSC pode acessado pela URL: http://glossario.libras.ufsc.br/
} 
Na Figura 2, o estágio inicial demonstra as quatro etapas descritas para construção do glossário, sendo assim, surge uma nova etapa, a de validação. Para a aprovação dos sinais, é necessária a aceitação por sujeitos surdos ou por especialistas em LIBRAS (ARAGÃO, 2015). Após esse processo, correspondendo ao estágio final, o glossário foi disponibilizado para a comunidade surda e interessados em geral. A etapa de validação será apresentada a seguir.

\section{A. Validação do Glossário}

A validação do glossário foi realizada em uma escola bilíngue de ensino médio da cidade de Rio Grande - RS. Participaram do experimento uma intérprete de LIBRAS, responsável pela pré-validação dos sinais do glossário, que também atua como diretora da escola, o professor de matemática e quatro alunos, entre 14 e 15 anos. Os sujeitos da pesquisa tiveram a identidade preservada, sendo citados apenas por números:

- Sujeito 1 - 14 anos: Comunicativo, esperto, confiante e disciplinado;

- Sujeito 2 - 15 anos: Introvertido, concentrado, inteligente e observador;

- Sujeito 3 - 14 anos: Dedicado e inteligente, porém agitado, tem dificuldade de concentração e insegurança em suas capacidades;

- Sujeito 4 - 15 anos: Tímido que pouco interage com os demais, organizado, atencioso e questionador.

O experimento foi conduzido pelos autores juntamente com dois bolsistas de graduação do grupo InfoEduc, semanalmente totalizando 12 encontros de $1 \mathrm{~h}: 30 \mathrm{~m}$. de duração. Os autores eram responsáveis por ministrar as aulas enquanto que um bolsista da área das ciências humanas tinha a função de documentar e observar o que acontecia na sala de aula, prestava suporte pedagógico ao experimento. $\mathrm{O}$ outro bolsista era responsável pelo suporte técnico e auxiliava os alunos, quando necessário. Sendo assim, os encontros ocorreram na disciplina de matemática com a presença do professor, que também atuava como intérprete. As atividades propostas foram direcionadas à educação de trânsito e, sendo assim, optou-se por construir os robôs Lego com o formato de veículos automotores com esteiras.

O Lego Mindstorms NXT é programado por meio de linguagem própria, que possui uma sintaxe semelhante com a linguagem $\mathrm{C}^{10}$, logo, para programar o robô, é necessário utilizar um ambiente de programação. Dentre os vários existentes, utilizou-se o Bricx Command Center. Nesse software são inseridos os comandos e funções para movimentação do robô e a comunicação entre eles é realizada por meio de uma interface, via USB preferencialmente. Para a realização das atividades utilizou-se um método de trabalho distinto, mencionado por DEUS (2013), que considera 4 princípios para ensino de alunos com surdez, apresentados a seguir:

- Favorecer a atividade dos alunos;

- Organizar as tarefas em pequenos grupos;

- Usar procedimentos visuais de comunicação;

- Proporcionar aos alunos diversas tarefas.

Realizou-se a apresentação do NXT, onde foram exibidos os comandos básicos para movimentação do robô. Cada comando foi explicado separadamente, bem como, suas funções, que permitiu aos sujeitos visualizarem a funcionalidade do robô. $\mathrm{O}$ glossário era utilizado em conjunto com o Bricx Command Center para consulta dos sinais ou a grafia dos comandos, quando necessário.

10 O “C” é uma linguagem de programação estruturada e procedural, sendo uma das mais populares no mundo. 
Na sequência, foi exposto aos sujeitos como o NXT realiza as curvas, processo que exige a percepção de qual das duas esteiras do robô, devem ser ligadas ou desligadas e a quantidade de tempo necessária a ser parametrizada nos comandos para realizar essa ação. Nas tarefas seguintes, os sujeitos programavam os robôs para percorrerem em circuitos pré-definidos, no qual eram explorados os conceitos de geometria, variáveis, sensores, estruturas de condição e procedimentos de aceleração e desaceleração dos robôs. Três desses circuitos são apresentados na Figura 3.
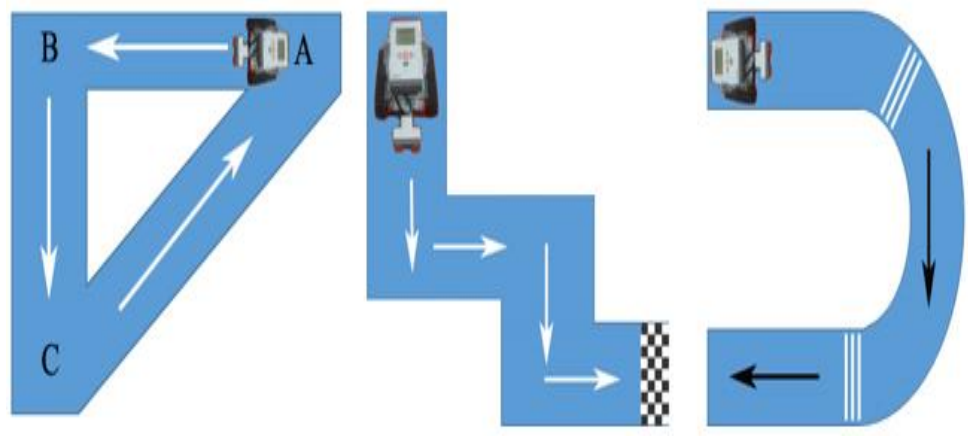

Figura 3 - Alguns dos circuitos usados nas atividades

Para verificar se os sujeitos construíram conhecimentos sobre os conteúdos abordados no Lego Mindstorms NXT, foi proposta uma atividade que consistia na elaboração de um circuito o qual os sujeitos deveriam sair do ponto 1 e escolher a melhor rota para os estacionamentos representados pelos pontos 2 e 3 . No trajeto deveriam respeitar o sentido das ruas e a sinalização, além de não invadir o gramado e prédios. A Figura 4 apresenta a ilustração do circuito.

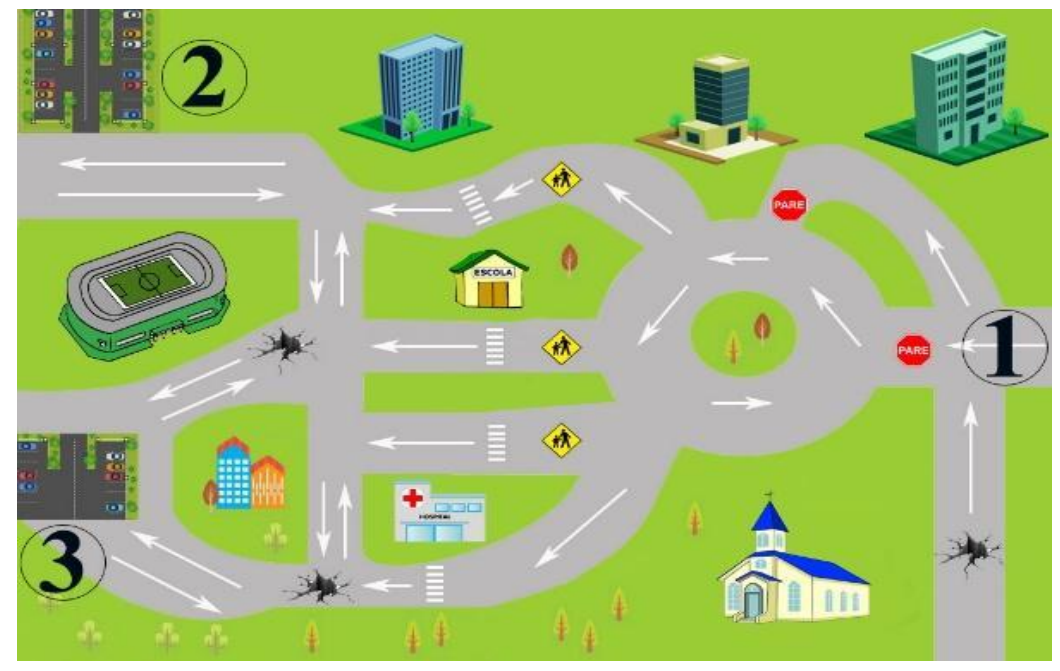

Figura 4 - Ilustração do Circuito

A Figura 4 demonstrou a ilustração do circuito para a atividade final do NXT, mas era necessário construí-lo no mundo real. Dessa forma, reproduziu-se a ideia por meio de fitas adesivas e desenhos impressos aplicados no piso de um laboratório de computação localizado na FURG. A Figura 5 mostra o circuito físico da atividade. 


CINTED-UFRGS Novas Tecnologias na Educação

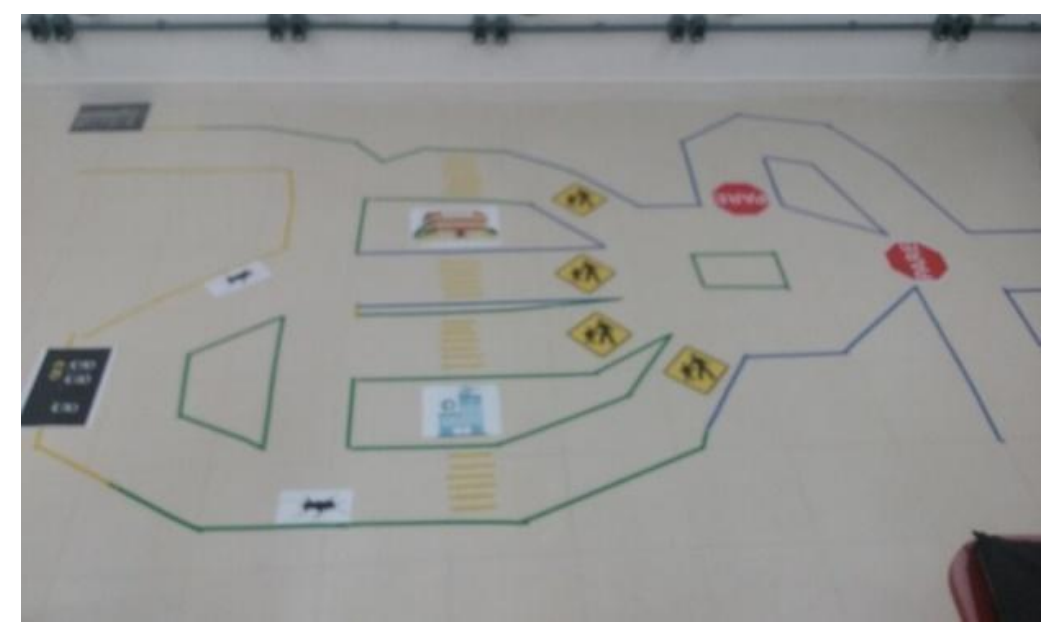

Figura 5 - Circuito representado no piso de um laboratório

Os dados de avaliação dos sujeitos foram obtidos por meio do método da observação direta intensiva, tipo de estudo que utiliza os sentidos (ver e ouvir) na obtenção de certos aspectos da realidade, bem como, examinar fatos ou fenômenos (LAKATOS, 2017). Além disso, aplicou-se questionários aos sujeitos durante o andamento das atividades e entrevista com o professor de matemática. Dessa maneira, a análise dos resultados do experimento e discussão serão apresentados na seção a seguir.

\section{ANÁLISE DOS RESULTADOS E DISCUSSÃO}

A avaliação do arcabouço pedagógico baseou-se na análise de conteúdo (BARDIN, 2015) que define um aglomerado de instrumentos metodológicos empregados em discursos variados, ou seja, é uma técnica de pesquisa que interpreta o pensamento do sujeito por meio de conteúdo expressos em textos (CAREGNATO, 2006).

Conduziu-se a análise dos dados da seguinte maneira: organização e digitalização das informações documentadas em sala de aula, transcrição da entrevista com o professor de matemática, leitura integral das respostas dos questionários. Além dessas atividades, para definir as categorias de avaliação, gerou-se um mapa mental dos relatórios de aula no formato digital com o Sobek Mining ${ }^{11}$. Dessa forma, emergiram 4 categorias de avaliação, sendo elas, conhecimento, compreensão, atenção e interação. As duas primeiras possibilitaram analisar o aprendizado dos alunos, já a categoria "atenção" permitiu avaliar o grau de interesse e curiosidade, enquanto que a "interação" propiciou a análise da comunicação e o relacionamento entre os sujeitos. As categorias conhecimento e compreensão podem ser encontradas na taxonomia de Bloom (FERRAZ, 2010). A estrutura das categorias de avaliação utilizadas podem ser observadas na Figura 6:

\footnotetext{
${ }^{11}$ Para mais informações sobre o Sobek Mining, acesse a URL: http://sobek.ufrgs.br/
} 


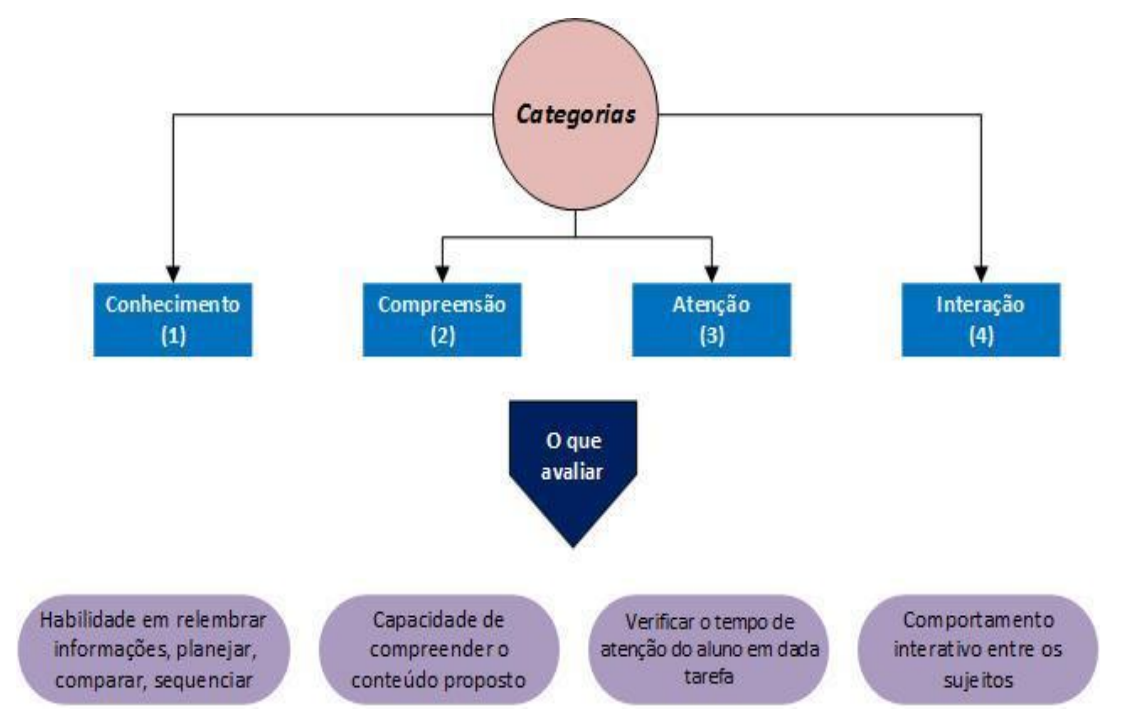

Figura 6 - Estrutura das categorias de avaliação

\section{A. Avaliação Pedagógica do Experimento}

Para a avaliação pedagógica dos sujeitos no experimento com o Lego Mindstorms NXT, é apresentada na Figura 7, as incidências das categorias nas atividades desempenhadas.

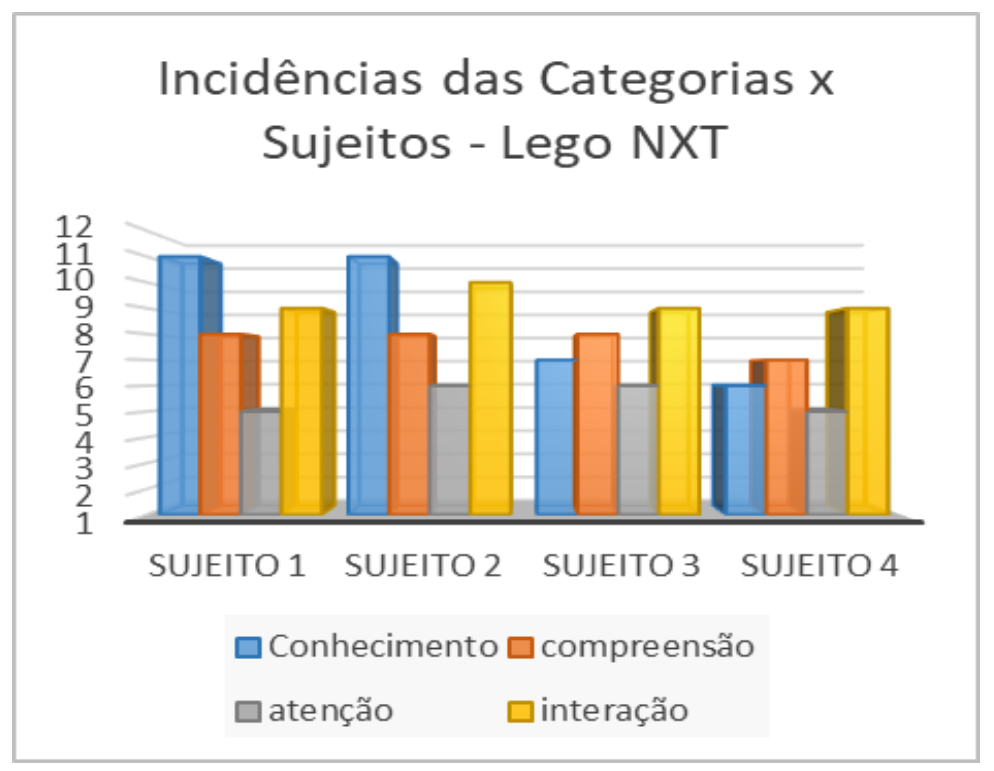

Figura 7 - Incidência das categorias

Sujeito 1 - Apresentou um índice alto de incidências na categoria conhecimento pois desenvolveu as atividades corretamente em todos os conteúdos abordados. Demonstrou desenvolvimento de raciocínio lógico ao trabalhar eficientemente na temporalização dos comandos, variáveis, processos em aceleração/desaceleração e estruturas de condição.

$\mathrm{Na}$ categoria compreensão teve um dos índices mais altos entre os sujeitos pois demonstrou entendimento dos comandos do robô e conteúdos abordados, porém inicialmente, não conseguia realizar as curvas. No decorrer dos encontros, compreendeu o vínculo entre os valores na temporalização dos comandos para realizar esse processo. Isso pode ocorrer porque os surdos possuem o raciocínio numérico menos desenvolvido, ou seja, podem não determinar corretamente vínculos entre códigos numéricos (MONTEIRO, 2005). 
Na categoria atenção, o sujeito obteve o menor valor entre seus pares, demonstrou pouca variação de atenção durante os encontros, porque em praticamente todas as situações, apresentou foco e concentração nas explanações e atividades. Na última categoria, apresentou um valor alto de incidências pois interagia frequentemente com os outros sujeitos nas atividades, para resolver um problema em grupo ou simplesmente para ajudá-los em suas tarefas individuais. No entanto, não interagiu somente na última atividade, pois a tratou como uma competição.

Sujeito 2 - Apresentou um comportamento e desenvolvimento de raciocínio lógico semelhante ao sujeito 1, na qual realizaram várias atividades em dupla e obtiveram em duas categorias o mesmo valor de incidências. Na categoria conhecimento, o sujeito inicialmente apresentou problemas ao trabalhar com o robô nos primeiros encontros, porém, nas tarefas seguintes demonstrou construção de conhecimento. Antes de iniciar cada atividade, tinha o hábito de planejar e comparar os códigos-fonte, procedimento que agilizava a programação no robô. Obteve o melhor aproveitamento da turma no circuito apresentado nas figuras 4 e 5, considerado o mais difícil. Apresentou o mesmo nível de incidências na categoria compreensão que os sujeitos 1 e 3. Compreendeu os conteúdos abordados e as atividades, mas no primeiro encontro não conseguia vincular a grafia de alguns comandos com os sinais do glossário porque estavam na língua inglesa. No entanto, após algumas explanações o problema foi solucionado. Isso pode ocorrer porque o surdo não bilíngue (ou em processo de alfabetização) pode apresentar adversidades na leitura ou escrita, como ordenação de palavras em frases, restrição de vocabulário e simplificação de termos (BISOL, 2010).

$\mathrm{Na}$ categoria atenção, o sujeito apresentou um dos índices mais altos do grupo, pois sempre se mostrou concentrado nas atividades. Na categoria interação, apesar de ser introvertido, em todas as atividades, comunicava-se frequentemente com seus pares para executar as tarefas e ajudá-los, quando necessário.

Sujeito 3 - Obteve um valor médio de incidências na categoria conhecimento. Apresentou problemas em algumas tarefas pois programava por tentativa e erro, sem planejamento algum, o que prejudicou o seu desempenho. No entanto, realizava as atividades propostas corretamente.

Na categoria compreensão, apresentou um índice de incidências semelhante aos sujeitos anteriores, pois demonstrou capacidade de assimilação dos conteúdos. Não desenvolvia corretamente algumas atividades, principalmente, as que exigiam raciocínio lógico-numérico (mudança frequente na direção do robô). $\mathrm{Na}$ categoria seguinte, diferentemente do sujeito 2 que era concentrado, o sujeito 3 teve um alto índice de incidências justamente por causa de seu comportamento disperso que demonstrou em praticamente todos os encontros, ou seja, déficit de atenção seletiva. Segundo (LUIZ, 2003), esse tipo de atenção caracteriza-se pela capacidade de selecionar entre vários estímulos, aquele que a mente deve permanecer focada, mantendo relevantes as informações na memória do indivíduo.

Na categoria interação, obteve um índice de incidências com um valor alto pois é um sujeito comunicativo. Em todos os encontros interagia com os seus pares, para conversar a respeito do conteúdo, tarefas ou para compartilhar o seu conhecimento. Comunicava-se frequentemente com o intérprete e pesquisador com o objetivo de esclarecer suas dúvidas, além do sujeito 4, seu par na maioria das atividades.

Sujeito 4 - Na categoria conhecimento, o sujeito 4 apresentou o menor índice entre a turma. Demonstrou falta de interesse na realização das atividades, porém as executava corretamente. Apresentou conhecimento sobre os comandos do Lego Mindstorms NXT e 
seu funcionamento. Na categoria compreensão, obteve um valor baixo de incidências. Após as explanações, programava corretamente e auxiliava seus pares quando necessário, isso demonstrou assimilação de conteúdo, porém, não apresentava o mesmo desempenho nos exercícios de fixação. Também apresentou um nível baixo de incidências na categoria atenção, pois era dispersa. Da mesma forma que o sujeito 3, poderia ter um melhor desempenho geral nas atividades porque errava frequentemente ao programar, não por falta de conhecimento, mas por desatenção. Na categoria interação, teve um índice alto de incidências conforme restante da turma. Era evidente a interação que o sujeito tinha com os seus pares, principalmente com o sujeito 3 .

No decorrer dos encontros os sujeitos apresentaram dificuldades na realização de algumas tarefas como percorrer o circuito com o robô no sentido inverso. Não conseguiam perceber a necessidade de inverter o caminho, ou seja, a direita vira esquerda e vice-versa. Isso pode evidenciar o baixo nível de compreensão do surdo em contextos complexos como pensamento abstrato e construção de sua subjetividade (ALVES, 2015). Os sujeitos também apresentaram dificuldades nas tarefas relacionadas a sensores e estruturas de condição, pois exigiam maior raciocínio lógico. Isso pode ocorrer porque os surdos são indivíduos que durante sua infância sofreram atrasos no progresso de suas habilidades metacognitivas, ou seja, a sua capacidade de entender a informação que lhe é demonstrada e na sua assimilação (BISOL, 2010). Dessa forma, apresentou-se avaliação pedagógica da pesquisa e, na sequência, as considerações finais.

\section{CONSIDERAÇÕES FINAIS}

Este artigo apresentou de que maneira ocorreu o experimento para estimular o raciocínio lógico em alunos surdos por meio de um glossário computacional de termos técnicos de computação em LIBRAS. Destacou-se a necessidade da construção do glossário e a elaboração dos sinais técnicos de computação. Como forma de validação realizou-se um experimento de estímulo à lógica de programação em uma escola bilíngue. O uso de um glossário técnico com palavras reservadas do Lego Mindstorms NXT propiciou aos sujeitos a construção de conhecimento sobre os conceitos básicos de programação e robótica, além de proporcioná-los as mesmas possibilidades de desenvolvimento educacional de seus colegas ouvintes.

Como forma de avaliação dos sujeitos foram estabelecidas 4 categorias que possibilitaram a análise de comportamento nas atividades para construção de conhecimento. Nela, foram realçados suas habilidades, restrições e dificuldades. Apesar dos sujeitos avaliados constituírem um grupo heterogêneo, com autonomia, construíram sua aprendizagem e desenvolvimento do raciocínio lógico de forma individual e coletiva por meio das atividades apresentadas. $\mathrm{O}$ arcabouço pedagógico combinado com $\mathrm{O}$ glossário pode oportunizar aos surdos acesso a cursos de computação e com perspectivas de frequentar um curso de ensino superior nessa área.

Em relação aos trabalhos futuros existe a intenção de aumentar a quantidade de termos técnicos para utilização do Lego Mindstorms NXT. Dessa maneira, pretende-se elaborar sinais para outros recursos como definição de macros e controle PID. Além disso, realizar alterações na interface do glossário para melhorar a acessibilidade e facilitar sua utilização. 


\section{REFERÊNCIAS BIBLIOGRÁFICAS}

ALVES, Elizabete G; Frassetto, Silvana S. Libras e o desenvolvimento de pessoas surdas, Canoas, Aletheia, v. 46, 2015.

ARAGÃO, Jamilly da S. et al. Um estudo da validade de conteúdo de sinais, sintomas e doenças/agravos em saúde expressos em LIBRAS, Ribeirão Preto, Revista LatinoAmericana de Enfermagem, v. 23, n. 6, p. 1014-1023, 2015.

BARDIN, L. Análise de conteúdo. Lisboa: Edições 70, 2015. 288 p.

BISOL, Cláudia; Sperb, Tania M. Discursos sobre a surdez: deficiência, diferença, singularidade e construção de sentido, Psicologia: Teoria e Pesquisa, v. 26, n. 1, p. 07$13,2010$.

CAREGNATO, Rita C. A; Mutti, R. Pesquisa qualitativa: análise de discurso versus análise de conteúdo, Florianópolis, Texto enferm, v. 15, n. 4, p. 679-84, 2006.

DEUS, Maria de L. F. Surdez: linguagem, comunicação e aprendizagem do aluno com surdez na sala de aula comum. Revista Anápolis Digital. Vol.3, n.1, 2013.

FERRAZ, Ana Paula. C. M; Belhot, Renato V. Taxonomia de Bloom: revisão teórica e apresentação das adequações do instrumento para definição de objetivos instrucionais. São Carlos, Gest. Prod., v. 17, n. 2, p. 421-431, 2010.

GRANADA, Rafael P. Glossarização de termos computacionais como estímulo à lógica de programação: um estudo de caso com alunos surdos. Dissertação de Mestrado. Centro de Ciências Computacionais. Universidade Federal do Rio Grande, Rio Grande. 2018. 104 p.

LAKATOS, E. M.; Marconi, M. de A. Metodologia do trabalho científico. $8^{a}$ ed. São Paulo: Atlas, 2018. 256 p.

LUIZ, Teumaris R. B; Araújo, P.F. Avaliação de um programa de atividade rítmica adaptada para variação dos parâmetros de velocidade do ritmo para pessoas surdas. Revista Brasileira de Ciência e Movimento. Brasília, v. 11 n. 3, p. 27-32, 2003.

MARTINS, Francielle C.; Stumpf, Marianne R. Coleta e registro de sinais-termos psicológicos para Glossário de Libras. Revista Leitura, v. 1, n.57, 2017.

MONTEIRO, Janine. K.; Galecki Clarissa A. Avaliação do raciocínio abstrato, numérico e espacial em adolescentes surdos. Canoas. Aletheia, n.21 p. 93-99, 2005.

PEREIRA, Débora F; Silva, Elvis N. Teclibras: Um Protótipo Web de apresentação de Termos de Informática em Libras. Rio de Janeiro, Revista Fórum. No. 33. 2016.

SILVA, Irenete M. dos S.; Santana, Beatriz P. Libras e Ensino Técnico: A necessidade de novos sinais. São Paulo, VII Jornada de Iniciação Científica - PIVIC Mackenzie/Mack Pesquisa. 2011.

VYGOTSKY, L. Obras Escogidas, T.5 - Fundamentos de la Defectologia. Madrid: Espanha. Editora Antônio Machado. $1^{\text {a }}$ Edição, 2012. 400 p. 